Research Paper

\title{
Total Synthesis of a Natural Product in Poly(ethylene glycol): ( \pm )-Centrolobine
}

ANNAREDDY SYAMPRASAD REDDY, RAMBABU CHEGONDI and SRIVARI CHANDRASEKHAR*

Division of Natural Products Chemistry, CSIR-Indian Institute of Chemical Technology, Hyderabad 500 007, India

(Received on 29 June 2015; Revised on 19 August 2015; Accepted on 21 August 2015)

\begin{abstract}
A natural product, $( \pm)$-centrolobine was synthesized using only one non-conventional solvent [poly(ethylene glycol)-400] as a reaction medium for all the reactions involved such as allylation of aldehyde, olefin metathesis, Wittig olefination followed by intramolecular oxa-Michael reaction and hydrogenation.
\end{abstract}

Graphical Abstract
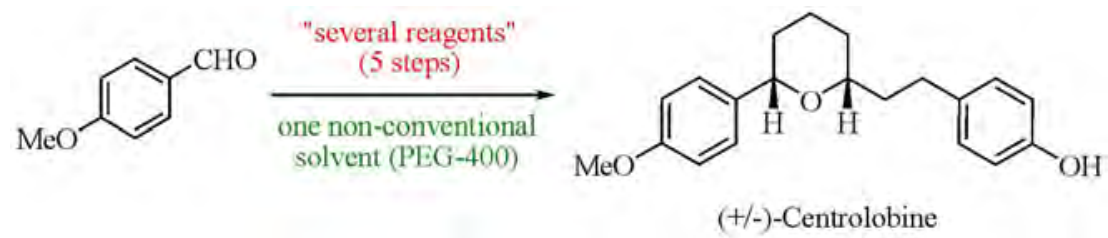

Keywords: Natural Product; Poly(ethylene Glycol); Centrolobine; Total Synthesis

\section{Introduction}

The use of volatile solvents in a chemical transformation occupies the maximum volume and recovery and/or minimizing this is an ever demanding process. Recently, we (Chandrasekhar et al., 2002; Chandrasekhar et al., 2003; Chandrasekhar et al., 2014) and others (Jiang and Ragauskas, 2006; Huaxing et al., 2005; Li et al., 2005; Zhang et al., 2004) have demonstrated a new solvent medium, poly(ethylene glycol) (PEG) as an eco-friendly system for various functional group transformations. The importance of PEG as a biologically compatible polymer for drug delivery is well demonstrated and well approved by FDA for internal consumption (Harris, 1992; Herold et al., 1989; Veronese et al., 2002). Thus, we believe the synthesis of any bioactive molecule in this solvent medium will certainly attract attention by both academic and pharma research groups. The efforts culminated in achieving the total synthesis of $( \pm)$ centrolobine in five steps including two one-pot reactions using poly(ethylene glycol) as a reaction medium in all the steps. Centrolobine (1, Fig. 1) is a tetrahydropyranic compound isolated from the heart wood of Centrolobium robustum (porcupine tree) and the stem of Brosimum potabile (Craveiro et al., 1970; de Albuquerque et al., 1964; Galeffi et al., 1965). The synthesis of $\mathbf{1}$ has attracted attention due to its activity against Leishmania amazonensis promastigotes; a parasite associated with

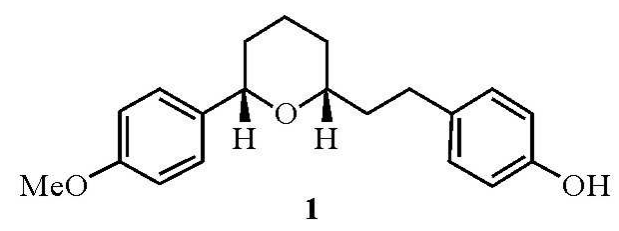

Fig. 1: ( \pm )-Centrolobine

*Author for Correspondence: E-mail: srivaric@iict.res.in; Fax: +91-40-27160512 
leishmaniasis [Leishmaniasis is a major health problem in Brazil. Leon and co-workers conducted a screen of traditional remedies from the Amazon rainforest to find new anti-leishmanial compounds. (-)-Centrolobine is one of the active ingredients in a herbal tea made from the wood of Cenrolobum robustum that is used by the native people of the Amazon as a tonic cure] (Araujo et al., 1998; Boulard et al., 2004; Colobert et al., 2002; Carreno et al., 2003; Chan and Loh 2005; Chandrasekhar et al., 2005; Evans et al., 2003; Latif et al., 2015; Marumoto et al., 2002).

\section{Results and Discussions}

$( \pm)$-Centrolobine should be obtainable from lactol 2 and phosphonate 3 via Wittig olefination followed by intramolecular oxa-Michael reaction as key steps. The lactol 2 was further synthesized from commercially available aldehyde $\mathbf{4}$ using allylation, olefin metathesis followed by hydrogenation reactions (Scheme 1). The

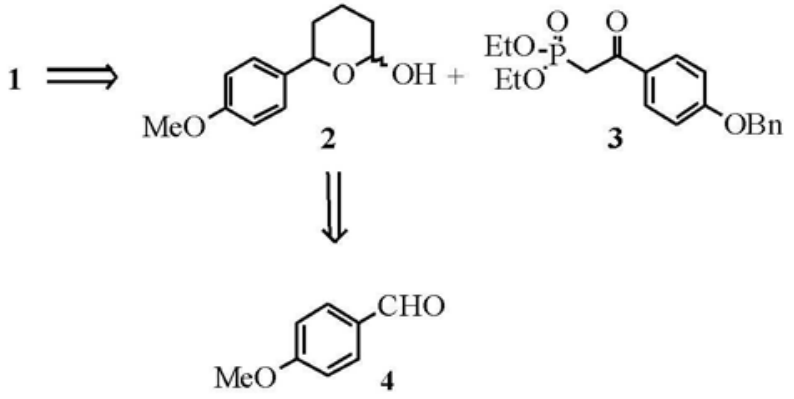

Scheme 1: Retrosynthesis of $( \pm)$-Centrolobine retrosynthetic strategy is designed in such a way that all reactions could be performed in PEG.

The synthesis began with the preparation of homoallylic alcohol 5 which was achieved by metal mediated allylation of aldehyde in the presence of Lewis acid catalyst (Scheme 2). We have subjected 4-methoxy benzaldehyde 4 with allyl bromide using zinc powder in poly(ethylene glycol)-400 in the presence of $\mathrm{CeCl}_{3} \cdot 7 \mathrm{H}_{2} \mathrm{O}$ as a Lewis acid catalyst. To the best of our knowledge this is the first example for allylation of aldehyde in PEG and could give the required product 5 in $89 \%$ yield. Encouraged by this result the recovery and reusability of the reagent system $\left(\mathrm{PEG} / \mathrm{Zn}-\mathrm{CeCl}_{3} \cdot 7 \mathrm{H}_{2} \mathrm{O}\right)$ was also tried, but to our disappointment the yield of the product is decreasing for each run [The reaction medium, solvent and reagents, was recycled after first run, used for second run which afforded 54\% yield and the third run gave only $32 \%$ yield of product 5 ]. Next task was the conversion of compound 5 to $\alpha, \beta$-unsaturated aldehyde $\mathbf{6}$ and was achieved by olefin metathesis in PEG again for the first time. The compound $\mathbf{5}$ was treated with acrolein in the presence of Grubbs $2^{\text {nd }}$ generation (Fürstner, 2000; Grubbs et al., 1995; Schrock and Hoveyda, 2003; Trnak and Grubbs, 2001) catalyst in poly (ethylene glycol)-400 for $24 \mathrm{~h}$ to afford the product 6 in $69 \%$ yield. The compound 6 was subjected to hydrogenation on $\mathrm{PtO}_{2}$ in PEG-400. This resulted in the formation of lactol $\mathbf{2}$ in quantitative yields. Yet another new one-pot Wittig olefination-<smiles>CCOCCOCC(=O)c1ccc(OC)cc1</smiles>
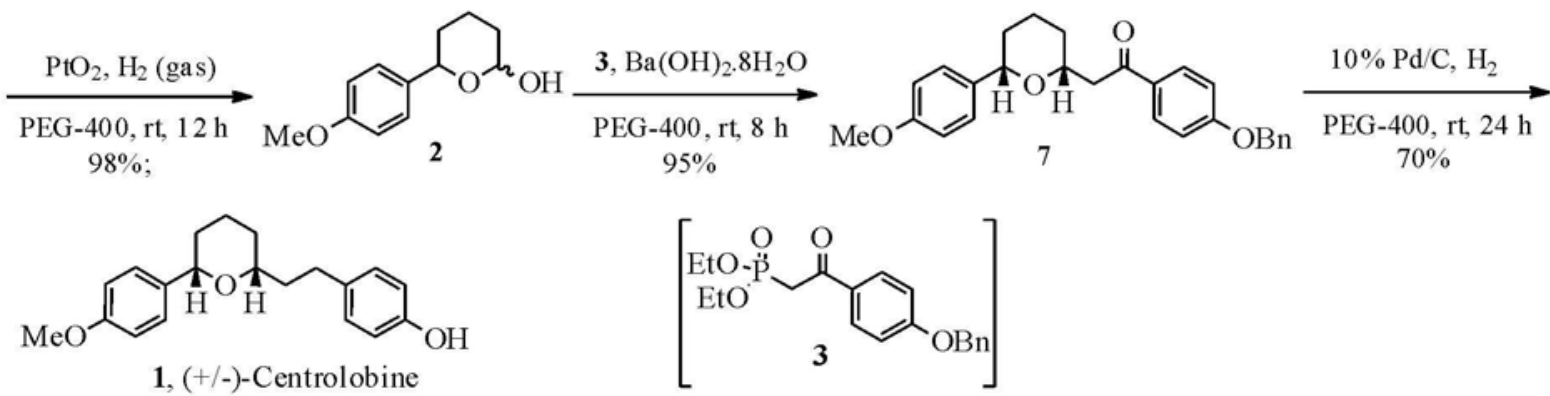

Scheme 2 : Total synthesis of $( \pm)$-Centrolobine in poly(ethylene glycol) 
intramolecular oxa-Micheal pyranylation was achieved in PEG-400 using known phosphonate $\mathbf{3}$ (Solladie et al., 1999) and $\mathrm{Ba}(\mathrm{OH})_{2}$ as base to realize the tetrahydropyranyl ether 7 with exclusive 2, 6- syndiastereoselectivity. The diastereoselectivity was unequivocally confirmed using detailed analysis of ${ }^{1} \mathrm{H}$ NMR spectral data [The relative configuration of $( \pm)$ centrolobine was confirmed by NOE enhancements as shown in Fig. 2]. Finally, debenzylation and deoxygenation of keto functionality in compound 7 was also accomplished in one-pot by hydrogenation in PEG, to afford the target molecule 1 in $70 \%$ yield.

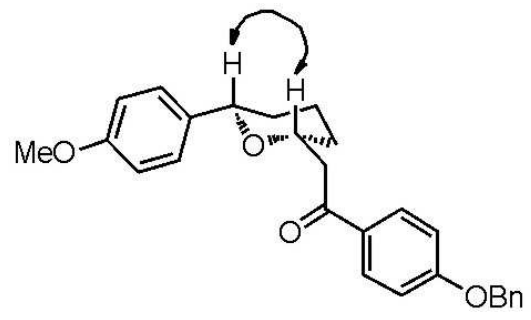

Fig. 2: NOE enhancements observed in compound 7

In all the steps, after completion of the reaction, the reaction mixture was diluted with anhydrous diethyl ether, stirred for $\mathbf{5}$ min and allowed to settle for $10 \mathrm{~min}$. Cooling in an ice-salt bath caused solidification of the PEG and the ether layer was decanted. This process was repeated twice to get the product into the ether layer and evaporation of the ether furnished the pure product, which can be used in next step without further purification except for second step (product $\mathbf{6}$ was purified by column chromatography). However, a small portion of the product in each stage was purified to take the analytical data. The spectral data of thus generated $( \pm)$-centrolobine (overall yield $40 \%$ ) was in full agreement with the ones reported for (-)-centrolobine (Galeffi et al., 1965). The use of PEG as a solvent (reusable solvent) allowed us to recover $\mathrm{Pd} / \mathrm{C}$ and $\mathrm{PtO}_{2}$ catalysts in hydrogenation reactions.

In conclusion, we have accomplished the total synthesis of a natural product with complete stereocontrol in poly (ethylene glycol) as a single solvent media for all the reactions involved. The solvent used for extracting the products in principle could be recycled if performed on large scale. The enantioselective synthesis of the same molecule using non-conventional solvents as reaction media is underway in our laboratory.

\section{Experimental Section}

All the commercial reagents were used without further purification unless indicated otherwise. All solvents were purified by standard techniques. Infrared (IR) spectra were recorded on Thermo Nicolet Nexus 670 spectrometer. Melting points are uncorrected. NMR spectra were recorded in $\mathrm{CDCl}_{3}$ on a Varian Gemini 200 and Bruker 300, NMR spectrometers. Chemical shifts $(\delta)$ are quoted in parts per million and are referenced to the tetramethylsilane (TMS) as the internal standard. Coupling constants $(J)$ are quoted in Hertz. Column chromatographic separations were carried out on silica gel (60-120 mesh). Mass spectra were obtained on Finnegan MAT 1020B or micro-mass VG 70-70H spectrometer operating at $70 \mathrm{eV}$ using direct inlet system.

\section{1-(4-Methoxyphenyl)but-3-en-1-ol (5)}

To a stirred suspension of $\mathrm{Zn}$ powder (260 mg, 4 mmol) in poly (ethylene glycol) (400 MW, $3 \mathrm{~g}$ ), was added $\mathrm{CeCl}_{3} .7 \mathrm{H}_{2} \mathrm{O}(37 \mathrm{mg}, 0.1 \mathrm{mmol})$, and aldehyde 4 (136 mg, $1 \mathrm{mmol}$ ) and allyl bromide (242 mg, 2 $\mathrm{mmol}$ ) at room temperature under nitrogen atmosphere. The stirring continued vigorously for 6 hours at the same temperature. The reaction mixture was diluted with diethyl ether $(5 \mathrm{~mL})$ and stirred for 5 min., cooled to $-10^{\circ} \mathrm{C}$ (ice-salt bath). The ether layer was decanted and the same ether treatment repeated twice $(2 \times 5 \mathrm{~mL})$. The combined ether layer was washed with water, brine and dried over anhydrous $\mathrm{Na}_{2} \mathrm{SO}_{4}$. The volatiles were evaporated on rotary evaporator to afford 5 ( $89 \%$ yield), which was used in next step without purification. The spectral data was identical with the literature data (Cai et al., 2004).

(E)-5-Hydroxy-5-(4-methoxyphenyl)pent-2-enal (6)

To a solution of homoallyl alcohol 5 (178 mg, $1 \mathrm{mmol})$ in poly (ethylene glycol) (400 MW, 2g) was added 
acrolein (224 mg, $4 \mathrm{mmol})$ and Grubbs ( $2^{\text {nd }}$ generation $)$ catalyst (42 mg, $0.05 \mathrm{mmol}$ ) under nitrogen atmosphere and the mixture was stirred at room temperature for $24 \mathrm{~h}$. The reaction mixture was diluted with diethyl ether ( $5 \mathrm{~mL}$ ) and stirred for $5 \mathrm{~min}$., cooled to $-10^{\circ} \mathrm{C}$ (ice-salt bath). The ether layer was decanted and the same ether treatment repeated twice $(2 \times 5$ $\mathrm{mL})$. The combined ether layer was washed with water, brine and dried over anhydrous $\mathrm{Na}_{2} \mathrm{SO}_{4}$. The volatiles were evaporated on rotary evaporator to afford crude compound $\mathbf{6}$, which was purified by silica gel column chromatography and the obtained pure product 6 (69\% yield) was used in next step. ${ }^{1} \mathrm{H}$ NMR $\left(\mathrm{CDCl}_{3}, 300 \mathrm{MHz}\right): \delta 9.42(\mathrm{~d}, J=7.5 \mathrm{~Hz}, 1 \mathrm{H}), 7.25$ $(\mathrm{d}, J=8.5 \mathrm{~Hz}, 2 \mathrm{H}), 6.88(\mathrm{~d}, J=8.5 \mathrm{~Hz}, 2 \mathrm{H}), 6.88$ $6.78(\mathrm{~m}, 1 \mathrm{H}), 6.17-6.08(\mathrm{~m}, 1 \mathrm{H}), 4.82-4.78(\mathrm{~m}, 1 \mathrm{H})$, $3.8(\mathrm{~s}, 3 \mathrm{H}), 2.84-2.65(\mathrm{~m}, 2 \mathrm{H}), 2.62(\mathrm{br} \mathrm{s}, 1 \mathrm{H}) ;{ }^{13} \mathrm{C}$ NMR (CDCl $3,75 \mathrm{MHz}): \delta 194.1,159.3,154.5,135.3$, 134.8, 127.0, 114.0, 72.5, 55.3, 42.3; IR (neat): $v 3443$, 2923, 2852, 1687, 1512, 1247, 1030, $830 \mathrm{~cm}^{-1}$; ESIMS $(\mathrm{m} / \mathrm{z}): 229.1(\mathrm{M}+\mathrm{Na})^{+}$.

\section{6-(4-Methoxyphenyl)-tetrahydro-2H-pyran-2-ol} (2)

To a solution of $\delta$-hydroxy $\alpha, \beta$-unsaturated aldehyde $6(206 \mathrm{mg}, 1 \mathrm{mmol}$ ) in poly (ethylene glycol) (400 MW, $2 \mathrm{~g}$ ) was added $\mathrm{PtO}_{2}(12 \mathrm{mg}, 0.05 \mathrm{mmol})$ under hydrogen atmosphere and stirred at ambient temperature $\left(25^{\circ} \mathrm{C}\right)$ for $12 \mathrm{~h}$. The reaction mixture was diluted with ether and stirred for 5 minutes at $0^{\circ} \mathrm{C}$ temperature. The ether layer was decanted and the procedure repeated for four times. The ether layer was decanted and the same ether treatment repeated twice $(2 \times 5 \mathrm{~mL})$. The combined ether layers were washed with water, brine and dried over $\mathrm{Na}_{2} \mathrm{SO}_{4}$. The volatiles were removed on a rotary evaporator to afford 2 (98\% yield), which was used in next step without purification. The compound $\mathbf{2}$, was confirmed by mass [ESIMS $\left.(\mathrm{m} / \mathrm{z}): 231(\mathrm{M}+\mathrm{Na})^{+}\right]$and used for further reaction.

\section{1-(4-(Benzyloxy)phenyl)-2,6-(4-methoxyphenyl)- tetrahydro-2H-pyran-2-yl)ethanone (7)}

To a solution of Horner phosphonate $\mathbf{3}$ (334 mg, 1 $\mathrm{mmol}$ ) in poly (ethylene glycol) (400 MW, $4 \mathrm{~g}$ ), was added activated $\mathrm{Ba}(\mathrm{OH})_{2} .8 \mathrm{H}_{2} \mathrm{O}(315 \mathrm{mg}, 1 \mathrm{mmol})$ under nitrogen atmosphere and stirred for 10 minutes. To this mixture was added, lactol 2 (208 $\mathrm{mg}, 1 \mathrm{mmol}$ ) at room temperature and stirring continued for $8 \mathrm{~h}$. The reaction mixture was diluted with diethyl ether $\left(10 \mathrm{~mL}\right.$ ) and stirred for $5 \mathrm{~min}$., cooled to $-10^{\circ} \mathrm{C}$ (icesalt bath). The ether layer was decanted and the same ether treatment repeated twice $(2 \times 10 \mathrm{~mL})$. The combined ether layer was washed with water, brine and dried over anhydrous $\mathrm{Na}_{2} \mathrm{SO}_{4}$. The volatiles were evaporated on rotary evaporator to afford 7 (95\% yield), which was used in next step without purification. The spectral data was in full agreement with the literature data.

\section{(士)-Centrolobine (1)}

To a solution of compound 7 (416 mg, $1 \mathrm{mmol})$ in poly (ethylene glycol) (400 MW, $3 \mathrm{~g}$ ) was added $10 \% \mathrm{Pd} /$ $\mathrm{C}$, one drop of conc. $\mathrm{HCl}$ under hydrogen atmosphere and stirred at room temperature for $24 \mathrm{~h}$. The reaction mixture was diluted with diethyl ether $(5 \mathrm{~mL})$ and stirred for 5 min., cooled to $-10^{\circ} \mathrm{C}$ (ice-salt bath). The ether layer was decanted and the same ether treatment repeated twice $(2 \times 5 \mathrm{~mL})$. The combined ether layers were washed with water, brine and dried over anhydrous $\mathrm{Na}_{2} \mathrm{SO}_{4}$. The volatiles were evaporated on rotary evaporator to afford crude compound 1 , which was purified by silica gel column chromatography to get the pure ( \pm )-centrolobine $\mathbf{1}$ in $70 \%$ yield. The spectral data of $( \pm)$-centralobine was in full agreement with the ones reported for (-)centrolobine.

\section{Acknowledgments}

ASR thanks CSIR, New Delhi, for research fellowship and RC thanks CSIR-Senior Research Associateship (Scientists' Pool Scheme) for financial assistance. SC thanks CSIR, Ministry of Science and Technology, Government of India. 


\section{References}

Araujo C A C, Alegrio L V and Leon L L (1998) Antileishmanial activity of compounds extracted and characterized from Centrolobium sclerophyllum Phytochemistry 49 751-754

Boulard L, BouzBouz S, Cossy J, Franck X and Figadere B (2004) Two successive one-pot reactions leading to the expeditious synthesis of (-)-centrolobine Tetrahedron Lett 45 6603-6605

Cai M, Huang Y, Zhao H and Zhang R (2004) Carbonyl allylation of aldehydes catalyzed by a silica-supported poly- $\gamma$ diphenylarsinopropylsiloxane palladium(0) complex $J$ Organomet Chem 689 2436-2440

Carreno M C, Mazery R D, Urbano A, Colobert F and Solladie G (2003) Reductive cyclizations of hydroxysulfinyl ketones: Enantioselective access to tetrahydropyran and tetrahydrofuran derivatives J Org Chem 68 7779-7787

Chan K P and Loh T P (2005) Prins cyclizations in silyl additives with suppression of epimerization: Versatile tool in the synthesis of the tetrahydropyran backbone of natural products Org Let 7 4491-4494

Chandrasekhar S, Narsimhulu Ch, Sultana S S and Reddy N R (2002) Poly(ethylene glycol) (PEG) as a reusable solvent medium for organic synthesis. Application in the Heck reaction Org Lett 4 4399-4401

Chandrasekhar S, Narsimhulu Ch, Sultana S S and Reddy N R (2003) Osmium tetroxide in poly(ethylene glycol) (PEG): A recyclable reaction medium for rapid asymmetric dihydroxylation under Sharpless conditions Chem Comm 1716-1712

Chandrasekhar S, Patro V, Chavan L N, Chegondi R and Grée (2014) Multi-component reactions in PEG-400: Ruthenium-catalyzed synthesis of substituted pyrroles Tetrahedron Lett 55 5932-5935

Chandrasekhar S, Prakash S J and Shyamsunder T (2005) Asymmetric synthesis of the pyran antibiotic (-)centrolobine Tetrahedron Lett 46 6651-6653

Colobert F, Mazery R D, Solladie G and Carreno M C (2002) First enantioselective total synthesis of (-)-centrolobine Org Lett 4 1723-1725

Craveiro A A, Prado A D C, Gottlieb O R and de Albuquerque P C W (1970) Chemistry of Brazilian Leguminosae. XX. Diarylheptanoids of centrolobium species Phytochemistry 9 1869-1875

de Albuquerque I L, Galeffi C, Casinovi C G and Marini-Bettolo G B (1964) Tetrahydropyran derivative isolated from centrolobium wood Gazz Chim Ital 94 287-295
Evans P A, Cui J and Gharpure S J (2003) Stereoselective construction of cis-2,6-disubstituted tetrahydropyrans via the reductive etherification of $\delta$-trialkylsilyloxy substituted ketones: Total synthesis of (-)-centrolobine Org Lett 5 3883- 3885

Fürstner A, Olefin metathesis and beyond (2000) Angew Chem Int Ed 39 3012-3043

Galeffi C, Casinovi C G and Marini-Bettolo G B (1965) Synthesis of centrolobine Gazz Chim Ital 95 95-100

Grubbs R H, Miller S J and Fu G C (1995) Ring-Closing Metathesis and Related Processes in Organic Synthesis Acc Chem Res 28 446-452

Harris J M (1992) Polyethylene Glycol Chemistry, Biotechnical and Biomedical Applications (Eds: Harris J M) pp 7, Plenum Press, New York and London

Herold D A, Keil K and Bruns D E (1989) Oxidation of polyethylene glycols by alcohol dehydrogenase Biochem Pharmacol 38 73-76

Huaxing Z, Yuhong Z, Leifang L, Hailiang X and Yanguang W (2005) $\mathrm{RuCl}_{3}$ in poly(ethylene glycol): A highly efficient and recyclable catalyst for the conjugate addition of nitrogen and sulfur nucleophiles Synthesis 13 2129-2136

Jiang N and Ragauskas A J (2006) Environmentally friendly synthesis of biaryls: Suzuki reaction of aryl bromides in water at low catalyst loadings Tetrahedron Lett 47 197200

Latif M, Yun J I, Seshadri K, Kim H R, Park C H, Park H, Kim H and Lee J (2015) Stereoselective construction of 2,6-cisdisubstituted tetrahydropyrans via intramolecular amide enolate alkylation: Total synthesis of (-)-centrolobine $J$ Org Chem 80 3315-3320

Li J -H, Zhu Q -M, Liang Y and Yang D (2005) Efficient and reusable $\mathrm{PdCl}_{2}\left(\mathrm{MeCN}_{2} / \mathrm{CuCl}_{2} / \mathrm{PEG}-400\right.$ system for cyclization of alkenyl $\beta$-keto esters and amides J Org Chem 70 5347-5349

Marumoto S, Jaber J J, Vitale J P and Rychnovsky S D (2002) Synthesis of (-)-centrolobine by Prins cyclizations that avoid racemization Org Lett 4 3919-3922

Molineux G (2002) Pegylation: engineering improved pharmaceuticals for enhanced therapy Cancer Treat Rev 28 13-16

Schrock R R and Hoveyda AH (2003) Molybdenum and tungsten imido alkylidene complexes as efficient olefin-metathesis catalysts Angew Chem Int Ed $\mathbf{4 2}$ 4592-4633

Solladie G, Wilb N and Bauder C (1999) First stereocontrolled synthesis of the $(3 S, 5 R, 7 R, 10 R, 11 R)-\mathrm{C} 1-\mathrm{C} 13$ fragment of nystatin $\mathrm{A}_{1} J$ Org Chem 64 5447-5452 
Trnka T M and Grubbs R H (2001) The development of $\mathrm{L}_{2} \mathrm{X}_{2} \mathrm{Ru}=\mathrm{CHR}$ olefin metathesis catalysts: An organometallic success story Acc Chem Res 34 18-29

Veronese F M, Caliceti P, Schiavon O and Sergi M (2002) Polyethylene glycol-superoxide dismutase, a conjugate in search of exploitation Adv Drug Delivery Rev 54 587-606

Zhang Z -H, Ying L, Wang Y -M, Liu J -Y and Li Y (2004), Indium tribromide in poly(ethylene glycol) (PEG): a novel and efficient recycle system for chemoselective deprotection of 1,1-diacetates Green Chem 6 563-565. 